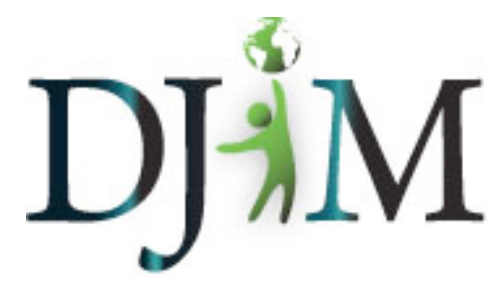

Volume 4 - Spring 2008 djim.management.dal.ca

\title{
Fostering a Balanced Library: How Practicing the Principles of the Slow Library Movement Could Lead to a Sustainable Future for Libraries
}

\section{Andrea Maria Norman}

\begin{abstract}
The increasing ubiquity of digital information in recent decades has altered the potential form and role of libraries of the future. In order to fulfill their most fundamental mandate, libraries must provide relevant programs and services to their communities. One compelling framework that could guide successful library planning for optimal relevance is that of the Slow Library Movement, first described by Mark Leggott, which involves six key concepts derived from the Slow Food Movement: education, community, local, craftsmanship, people and enjoyment. These concepts have been successfully applied in other disciplines, notably that of education. This paper contains a detailed description, evaluation and elaboration of the framework of the Slow Library Movement.
\end{abstract}

\begin{abstract}
About the Author: Andrea Norman is currently a student at the School of Information Management at Dalhousie University. She earned a Bachelor of Science with a double major in Psychology and English from the same institution. This paper was researched and written for the Information in Society course in the School of Information Management.
\end{abstract}




\section{Introduction}

Information and communications technologies are relatively recent developments that have changed the relationship between libraries and society. As digital technologies continue to evolve and advance, there is much speculation about how information and knowledge will be created, disseminated and stored in the future and where libraries will fit in this environment. The vision of an entirely digital existence of information, eliminating the need for physical libraries, has become prevalent during the past 20 years (Crawford, 1999). Many are asking: "Will libraries disappear as the world goes WiFi - will Google become the future library?" (Inayatullah, 2007, p. 54) How libraries respond affects their plans and actions; if their predictions are misguided, quality of services may suffer. Examining the digital revolution thus far, Crawford (1999) argues that the "all-digital future...lack[s] historical and factual basis" ( $p$. 1 ), the most realistic view is of a complex mix of "media, services, and partnerships" (p. 3) and that striving for 'Balanced Libraries' (Crawford, 2007) is the best approach. The Slow Library Movement (SLM), first described by Mark Leggott in 2006 and inspired by the Slow Movement, provides a framework for fostering the growth of sustainable, balanced libraries that will contribute in relevant and meaningful ways to society in the years to come. Principles of the SLM will be described and elaborated upon using concepts and examples from the realm of education, where the Slow Movement has led to reforms in the goals, structure and provision of schooling.

\section{Background}

Since Mark Leggott derived the principles of the SLM from the broader Slow Movement, a thorough explanation of the SLM must begin with a description of the origins and principles of the Slow Movement. Many of the values and principles of the Slow Movement shown here will resurface later in the discussion of the SLM. The Slow Movement began in Italy with a group committed to "creat[ing] awareness of local products and awaken[ing] people's attention to food and wine and the right way to enjoy them" (Petrini, 2001, p. 4). Members coined the term 'Slow Food' during a 1986 demonstration against the opening of a McDonald's restaurant in the Piazza di Spagna in Rome, and in 1989 the international Slow Food Movement (SFM) officially launched with the signing of a Manifesto (Petrini, 2001; Slow Food, 2006). It is important to note 'slow' was not used in the context of speed. Rather, Slow Food was intended to stand for "everything that McDonald's does not: fresh, local, seasonal produce; recipes handed down through the generations, sustainable farming [and] artisanal production" (Honoré, 2004, p. 59). Slow Food is in opposition to "the fast-food values that threaten to homogenize and industrialize our food heritage" (Waters, 2001, p. xiv).

Biodiversity is a significant concern, not just in the interest of gustatory variety and richness of flavours, but because of the risk of producing food in unsustainable ways, where sustainability 
requires meeting current needs without lessening the ability of future generations to meet their needs (Capra, 2005a). Less diversity in farming affects the balance of ecosystems and increases the threats posed by virus and disease (Honoré, 2004). As we promote homogeneity through current practices, we are irreversibly compromising the health and opportunities of those who follow us. In order to achieve biodiversity, the SFM values and supports species of plants and animals native to local regions (Footprint Choices, 2007a). Preservation and reverence for local community and culture are practiced, (Holt, 2005) which are interdependent with biodiversity.

The SFM has influenced a broader "cultural shift towards slowing down" (Footprint Choices, 2007c) in such diverse realms as public administration, organizational management, medicine, exercise, education and family life, to name just a few. Resistance to an increasing pace of life is nothing new. The cultural push against the speed-centric ethos of the industrial revolution is a notable historical example. What is unique is that this sentiment is "moving into the mainstream with more urgency than ever before" (Honoré, 2004, p. 14).

The broader Slow Movement tends toward a greater emphasis on speed than the SFM, highlighting the potential benefits of literally slowing down and the harmful effects of too accelerated a pace, although conscientious supporters attempt to maintain a comprehensive meaning of 'slow' as "a way of being:" living in a "calm, careful, receptive, still, intuitive, unhurried, patient, reflective, quality-over-quantity" manner (Honoré, 2004, p.14). Subtleties in explanations of the Slow Movement differ, but there is agreement among proponents that the essence is balance and connection (Footprint Choices, 2007c; Honoré, 2004). The Movement targets the "overarching problem of disconnection: of rural communities from urban life, of food from people's understanding of its origins, [and] of health from the environment" (Barlow \& Stone, 2005, p. 5).

One of the areas where the Slow Movement has already had an impact is in education:

Fast schools like fast food are not concerned with the process, preparation and connection. They are concerned with the standardised end product[s], which in the case of schools [are] the results from standardised tests and targets, and in the case of food [are] the standardised hamburger[s] or fried chicken... (Footprint Choices, 2007b)

The Center for Ecoliteracy, now over 10 years old, provides resources, assistance and guidance to educational institutions and communities interested in an alternative to Fast Schools, suggesting "education for sustainable living" be the guiding mantra (Barlow \& Stone, 2005; Center for Ecoliteracy, 2007). Participants in the program incorporate community-based activities into the curriculum, giving students practical experience and a sense of connection. 
For example, in the Edible Schoolyard program, students create and maintain a garden from which they prepare school lunches, learning about their local ecosystem in the process. These initiatives have exhibited considerable benefits, success and international renown (Waters, 2005). Because schools and libraries are public institutions sharing responsibility to promote and preserve cultural diversity, among other similarities, the experience of applying Slow Movement principles in education should be used to inform the SLM.

Although the term "McLibrary" would make many librarians and patrons uncomfortable, it has been used in serious and informed discussion to describe the potential future of libraries (Inayatullah, 2007, p. 55). At first glance, libraries and fast food, or information and fast food, may not seem to have much in common. However, many of the values implied by the ubiquity of the fast food industry are also implied in the information industry. Fast food gives the impression that food is "cheap," and plentiful, that "eating is primarily about fuelling up in as little time as possible," food "should taste the same everywhere" and where it comes from is unimportant (Waters, 2005, pp. 51-52). Likewise, the explosion of availability and abundance of information, and how libraries operate, suggest to patrons that information is cheap and plentiful, that searching, evaluating and using information is a race to the finish line, that information origin is irrelevant and content and form should be identical everywhere.

Information is a means to an end and the faster one can obtain the information and get it over with, the better. However, information can be expensive and rare. Careful attention and devotion to information search, retrieval and use is valuable and should not be rushed. Information sources unique to a particular community are precious resources and the context of information creation affects meaning. In comparing schooling to fast food, Ableman (2005) states the education system "treat[s] us all as if we are just consumers, passively waiting to be fed disconnected information or pre-packaged food" (p. 178). I would argue this is an apt assertion in the context of libraries as well.

John Miedema (2007b) has suggested that the language shift in libraries, to 'information' and away from 'books', may be unduly placing emphasis on electronic resources and devaluing fiction and literature collections, which are still primarily print resources. He asserts that reading an entire book in a purposeful, attentive and unhurried manner provides understanding and knowledge that cannot be achieved via electronic media: "the end of books is the end of deep thought" (para. 8). I think the print versus electronic issue is more complex and cannot be summed up in a cut and dry statement. There is no reason slow reading cannot be achieved electronically, although it may be more difficult and may not be possible for all. The key is acknowledging the value of print and not pitting it against electronic. The reality of tightening budgets requires libraries to make value judgements with respect to the two types of media and as Miedema rightly points out, it is unwise to assume electronic is always better. 
Leggott's description of the SLM indicates recognition of the complexity of the issues surrounding changing technologies and the uncertainty of the future. The SLM is most certainly not anti-technology; digital technologies actually provide the means to put into practice many aspects of the SLM, primarily via the development of open source software. As will be shown, open source software is a tool that can facilitate each element of the SLM. The framework of the SLM is composed of six key concepts derived from the SFM: education, community, local, craftsmanship, people and enjoyment (Leggott, 2007a). This paper will highlight the origins of each concept as it was used in the SFM context and explain it in terms of its implications for library practice.

\section{Education}

The SFM encourages people to become educated about the connection between where their food comes from, how it is prepared and the implications for health, environment and sustainability. This knowledge should then be used to inform future food choices that are responsible and aware. Food choices can then affect and be affected by food sources. Innovations such as the Edible Schoolyard challenge the hierarchical, traditional structure of the education system. Students play an active role in what and how they are learning, resulting in an "experiential, participatory, and multidisciplinary" classroom environment (Capra, 2005a, p. xiv). The education system and community both teach and learn from students, and students learn from one another, in a cycle comparable to that of food choices and sources.

In libraries, Leggott (2007a) argues that learning must be similarly "bidirectional," with librarians, members from other professions and disciplines, and patrons learning from one another. Libraries should be open to learning from any and all areas, not just library and information science. Learning is not a linear process, as the content and tools used to obtain knowledge during one phase initiates the creation of "new tools and content" during subsequent phases, resulting in a sustainable cycle of education (Leggott, 2007a).

To connect members of this learning community, libraries can use open source software that allows all members to contribute and shape content and tools. Open source describes computer software that includes the entirety of the source code, which enables any and all users to alter it or use it to derive additional software in order to meet their specific needs and preferences (Leggott, 2007d). Using open source, libraries can develop systems and tools designed specifically for the unique and dynamic needs of their community that are capable of adjusting according to feedback. Libraries benefit through improved system and content capability and functionality and the community then has access to more usable and functional library services. In this way, libraries can both teach and learn from their community in a mutually beneficial and sustainable cycle. 


\section{Community}

Instead of apocalyptic proclamations about the end of libraries, Leggott (2007a) points to fostering involvement with, and preservation of, the community as a role for libraries that is unchallenged, even by an all-digital future. Both the SFM and SLM stress the importance of an outlook contextualized by the particular ecosystem or community in which we exist. Libraries should "recognize [and use] the passion and skills of both staff and patrons [to] build [the] community around information" (Leggott, 2007d, p. 20).

While the SLM is distinct from Web 2.0 and Library 2.0, examples of what these concepts mean can illustrate how community building can be achieved in the digital age. Web 2.0 can be defined as "leveraging the net as a framework to build community and knowledge, with data as the bricks enabling the creation of durable services and resources accessible to all systems and people, resulting in an ever-evolving and rich user-centric experience" (Leggott, 2007d, p. 10). Library 2.0 is Web 2.0 applied to the whole library, including, and beyond, the technology context, with overwhelming focus being the ability of the community to participate (Leggott, 2007d).

Two examples that clarify this component of the SLM are social tagging and the writeable catalogue (Miedema, 2007a). Social tagging enables anyone to create and attach subject terms to resources, including websites and items in a library catalogue. These subject tags can be used by the 'tagger' or anyone else who finds the subject terms helpful in locating, organizing or using the information. This concept recognizes that the same information source can have multiple meanings to different groups, and an individual cataloguer could never discover all the subject terms that could be useful for a given item. Allowing users to attribute subject terms increases community engagement, and creates a local context for the item, as different communities will see unique connections and meanings. If users are able to tag items in the catalogue, the tags will become a unique and localized resource relevant to the specific community.

Leggott (2007b) is implementing a Virtual Research Environment (VRE) at the University of $\mathrm{PEI}$, which provides portals that connect individual research communities at the university with each other and with the tools, resources and information they need. Researchers can edit the content of these portals to ensure they remain as timely and relevant as necessary. Prior to this program, it was the responsibility of research communities to organize themselves and seek out relevant resources, typically involving visits to a multitude of separate websites and portals. The library did not recognize these communities by providing any special services; the library and the research groups were disconnected from each other. 
Leggott (2007a) argues libraries need to reconnect to the community in the same way that the SFM strives to reconnect people to food, and in doing so, with their community. Web and Library 2.0 tools should be "built into traditional library sites... and integrate[d]....into the places patrons go" (Leggott, 2007b, p. 88). Patrons will be more invested in the community if they contribute (Leggott, 2007c) and will feel more committed and responsible, encouraging them to continue to build the library. "Sustainability always involves a whole community. "This is the profound lesson we need to learn from nature." (Capra, 2005b, p. 24).

The SFM, and reforms to education it inspired, emphasize that a particular ecosystem or community is a complex system and working towards sustainable food practices requires respect for the rules of these systems. Libraries are also complex systems of dynamic "mix of media, collections, access, services and partnerships" (Crawford, 1999, p. 3) and I suggest that working towards sustainable libraries must also be cognizant of the rules of systems and abide by them. Remember that reconnecting to the community and achieving balance are the two fundamental values of the Slow Movement. Since achieving harmony and connection are of such importance, the rules of complex systems will be described in some detail as a guideline for libraries in pursuit of balance.

Before implementing any changes, it is important to get to know the history and current behaviour of the system without any preconceived expectations, and to continue to constantly monitor the system and learn more about it (Meadows, 2005). It is easy to become too enthusiastic about new services and change things too quickly. Libraries should continually step back and take a look with an unbiased eye at the library system and its place in the broader system of the community.

"The forces and structures that help the system run itself" should be supported rather than creating competing or interfering processes (Meadows, 2005, p. 197). In a culture with truisms like 'change is the only constant,' libraries may replace services that have no business being altered, simply for the sake of calling it progress.

When working within a complex system, consider as many alternatives as possible by thinking outside the box, and allow for opinions to be swayed by others through carefully constructing and maintaining feedback mechanisms (Meadows, 2005). The standard business model trains us to think in quarterly and yearly terms but these are constructs and not natural attributes of the system. Current practice can have indefinite effects, so it is important to think into the distant future. All stakeholders in the system should have the opportunity to weigh in on decisions and modify or replace anything being considered, even if that involves rejecting preliminary convictions. "Pay attention to what is important, not just what is quantifiable. Our culture...has given us the idea that what we can measure is more important than what we can't" (Meadows, 2005, p. 201). Those who contest or challenge library funding often expect 
and respect numbers that support library services over quality measures. This causes libraries to attend more to circulation or traffic statistics than the things that do not come with numbers attached.

"Total system properties, such as creativity, stability, diversity, resilience, and sustainability" (Meadows, 2005, p. 201) should be the focus rather than smaller parts of the system. It's useless if one part of the system is functioning perfectly if the whole system has failed. This seems too simple to require articulation, but examples of failure to adhere to this rule are pervasive. For example, particular departments within failing organizations often have stellar performances. This returns us to the need for community and connection at the center of the Slow Movement. "What we have really lost in both our food system and our education system [and library system] is context, a sense of how things relate to each other...[we] need to understand whole processes and the interconnection of all things" (Ableman, 2005, p. 179).

\section{Local}

The SLM advocates using local tools and talent whenever possible, modelled after the SFM practice of supporting local suppliers and native varieties of food sources. Instead of paying high prices for services that are inflexible and outside the control of the local library, Leggott (2007a) promotes using open source software that library staff can build and modify to meet the unique needs of the library community. This requires a commitment of staff training and time, however the library will have saved significantly by not having to purchase and support inflexible vendor products. In contrast with "large-scale, centralized systems...smaller-scale technologies are often cheaper and more resilient and...vastly expand the potential...to meet human needs on a sustained basis" (Orr, 2005, p. 93).

In order to truly connect with the community, libraries need to become inhabitants rather than residents: "a resident is a temporary occupant, putting down few roots and investing little, perhaps caring little for the immediate locale...The inhabitant, in contrast, dwells... in an intimate, organic, and mutually nourishing relationship with a place" (Orr, 2005, p. 92). Supporting local resources and talent whenever possible can make the resident library an inhabitant by taking nourishment from and providing nourishment to the community. As this explanation suggests, the local and community concepts of the SLM are very closely related.

\section{Craftsmanship}

According to the SFM, particular attention must be paid to using the best ingredients in preparing food, and these ingredients should be prepared according to local cultural traditions. Cooking is a craft transferred from one generation to the next. In the context of libraries, the 
right components, features ${ }_{2}$ and tools are important 'ingredients' in the creation of the best services and the only way to achieve the local component is by using open source software (Leggott, 2007e, February 27).

The participation of the community is relevant within the concept of craftsmanship as well: "the net provides...an incredible landscape for the creation of digital tapestries. The challenge for us is to harness the passion and knowledge of library staff to provide the tools and services to help weave" (Leggott, 2007d, p. 3). If given the opportunity, the community can craft locally relevant library content through the use of Web and Library 2.0 technologies.

\section{People}

Proponents of the SFM value the experience, expertise and creativity of the people involved in the cultivation and preparation of traditional, local foods. Agricultural and culinary practices are handed down through generations, fostering unique species, recipes and resulting tastes. The knowledge resides in the teaching and practicing of these traditions and largely cannot be found in written form, making people the most valuable resource in maintaining diversity and ensuring traditions survive.

In the context of the SLM, "tomorrow's librarians must continue to pay attention to the most important aspect of library service: people" (Crawford, 1999, p. 29). Library staff and patrons are more important than the technologies they create and use (Leggott, 2007a). Open source and Web and Library 2.0 are wonderful tools but cannot be compared with the abilities and passion of the people involved in the system. As with the SFM, the experience, expertise, creativity and intelligence of human beings is not replaceable or expendable.

\section{Enjoyment}

The SFM has always been transparent with respect to their policy of taking pleasure in food and local community and culture. Pleasure is just as important as biodiversity and tradition because it allows us to experience why these are being preserved. If we obtain enjoyment from something we will inherently value it and resist losing it more strongly. Healthy food is supposed to taste good and provide pleasure and the process of enjoying the foods we prepare is a natural part of the cycle.

Likewise, although the SLM involves much more work and commitment than the name may at first suggest, there are plenty of opportunities for enjoyment. People are social, and increasing the communication and connection between the library and community will lead to pleasurable interaction. A greater sense of involvement and control when using participative and open source tools gives staff and patrons a sense of satisfaction over what they have contributed to. Rather than feeling frustrated with the faultiness of a particular service or tool, librarians 
and patrons should be given the power to change and improve it, providing a sense of accomplishment and time well spent. Lessons learned from working with complex systems teach us to "celebrate complexity" (Meadows, 2005, p. 204). During the process of working towards a Slow Library, we should take pleasure in recognizing and discovering the abilities of staff and patrons, the scope and potential of the library's resources and the unique attributes of the local community.

\section{Conclusion}

The essence of the Slow Movement is composed of balance and connection which run through each of the six key concepts of the SLM described above: education, community, local, craftsmanship, people and enjoyment. If connection is favourable, it makes sense that the concepts of the SLM themselves are highly interconnected. Surprisingly, the idea of actual speed is notably absent from the framework. While not a "war against speed" (Honoré, 2004, p. 4), the Slow Movement legitimately calls into question the increasing over-valuation of speediness. In many cases faster is not better and can often compromise quality. "Managing a social system... means finding the optimal values" (Capra, 2005b, p. 28) not the maximum values. Libraries are often guilty of implementing the newest and fastest systems at the expense of providing better quality products or services for their community.

In reviewing the key concepts and meaning of the SLM, I would suggest Balanced Libraries to be a more practical term because of the unfortunate negative connotations of 'slow.' The "secret" of the Slow Movement is "balance: instead of doing everything faster, do everything at the right speed" (Honoré, 2004, p. 275). In line with the SLM is Crawford's call for balanced libraries:

A library system that stands still is unstable and headed for trouble. A library staff that is obsessed with Hot New Things and aiming for new users at the expense of familiar services and existing patrons is unbalanced and headed for trouble....the extremes make no sense. Every library...should work toward balance...that clears the way for progress without abandoning the heart, soul and history of a library and its community (2007, p. 1).

There is evidence that reverence for technology and speed is being questioned in society (Callenbach, 2005), indicating that people may be becoming increasingly more receptive to alternatives. They may want and support a library that fosters community, participation, diversity and local content rather than a McLibrary, a source of the same mass-marketed and mass-produced products and services identical to those of libraries across the country. One of the other four potential futures for libraries in the discussion previously mentioned is what appears very similar to a Slow/Balanced Library: the library as that of community builder 
(Inayatollah, 2007). There is no reason to think the participants in the discussion had heard of the concept of the SLM so their projection of the library as community builder is promising because it suggests that the concepts of the SLM could have a welcoming audience who would put these ideas into practice. Mark Leggott has applied the slow-fast dichotomy of the Slow Movement to libraries, and has shown that the shoe fits, that libraries could benefit from an evaluation and restructuring through the lens of the Slow Movement. Libraries could join the ranks of the diverse and growing group that have devised practical and valuable applications of the Slow Movement philosophy. 


\section{References}

Ableman, M. (2005). Raising whole children is like raising good food: Beyond factory farming and factory schooling. In Z. Barlow \& M.K. Stone (Eds.), Ecological literacy: Educating our children for a sustainable world (pp. 175-183). San Francisco: Sierra Club Books.

Barlow, Z., \& Stone, M.K. (Eds.) (2005). Introduction. In Ecological literacy: Educating our children for a sustainable world (pp. 1-8). San Francisco: Sierra Club Books.

Callenbach, E. (2005). Values. In Z. Barlow \& M.K. Stone (Eds.), Ecological literacy: Educating our children for a sustainable world (pp. 45-48). San Francisco: Sierra Club Books.

Capra, F. (2005a). Preface: How nature sustains the web of life. In Z. Barlow \& M.K. Stone (Eds.), Ecological literacy: Educating our children for a sustainable world (pp. xiii-xv). San Francisco: Sierra Club Books.

Capra, F. (2005b). Speaking nature's language: Principles for sustainability. In Z. Barlow \& M.K. Stone (Eds.), Ecological literacy: Educating our children for a sustainable world (pp. 18-29). San Francisco: Sierra Club Books.

Center for Ecoliteracy. (2007). About: Our mission. Retrieved 19 November, 2007, from http://www.ecoliteracy.org/about/index.html.

Crawford, W. (1999). Being analog: Creating tomorrow's libraries. Chicago: American Library Association.

Crawford, W. (2007). Preview. Balanced libraries: Thoughts on continuity and change. Morrisville, NC: Lulu. Retrieved November 18, 2007, from http://www.lulu.com/browse/preview.php?fCID=737992.

Footprint Choices. (2007a). Slow food. Retrieved November 18, 2007, from http://www.slowmovement.com/slow_food.php.

Footprint Choices. (2007b). Slow schools and slow education: Connecting children to life. Retrieved November 18, 2007, from http://www.slowmovement.com/slow_schools.php.

Footprint Choices. (2007c). The slow movement: Making a connection. Retrieved November 18, 2007, from http://www.slowmovement.com/. 
Holt, M. (2005). The slow school: An idea whose time has come. In Z. Barlow \& M.K. Stone (Eds.), Ecological literacy: Educating our children for a sustainable world (pp. 56-63). San Francisco: Sierra Club Books.

Honoré, C. (2004). In praise of slow: How a worldwide movement is challenging the cult of speed. Toronto: Vintage Canada.

Inayatullah, S. (2007). Which future for libraries? [Electronic version]. Foresight, 9(3). 54-57.

Leggott, M. (2007a). Ahhh...the beauty of slow. Retrieved November 11, 2007, from http://loomware.typepad.com/slowlibrary/2007/02/ahhhthe_beauty_.html.

Leggott, M. (2007b). Library 2.0: Threads in the tapestry. Retrieved November 11, 2007, from http://loomware.typepad.com/loomware/aboutme.html.

Leggott, M. (2007c). May the source force be with you. Retrieved November 11, 2007, from http://loomware.typepad.com/loomware/aboutme.html.

Leggott, M. (2007d). Weaving a digital tapestry: Capacity building in the digital age. Retrieved November 11, 2007, from http://loomware.typepad.com/loomware/aboutme.html.

Leggott, M. (2007e, February 27). [Msg 9]. Message posted to http://www.librarian.net/stax/1928/slow-library-a-20-idea/.

Meadows, D. (2005). Dancing with systems. In Z. Barlow \& M.K. Stone (Eds.), Ecological literacy: Educating our children for a sustainable world (pp. 193-205). San Francisco: Sierra Club Books.

Miedema, J. (2007a). The slow library movement. Retrieved November 11, 2007, from http://www.accessola2.com/olita/insideolita/wordpress/?p=46.

Miedema, J. (2007b). Will slow reading be a casualty of fast libraries? Retrieved November 11, 2007, from http://johnmiedema.wordpress.com/2007/04/30/will-slow-reading-be-acasualty-of-fast-libraries/

Orr, D. W. (2005). Place and pedagogy. In Z. Barlow \& M.K. Stone (Eds.), Ecological literacy: Educating our children for a sustainable world (pp. 85-95). San Francisco: Sierra Club Books. 
Petrini, C. (2001). Slow food: The case for taste. (W. McCuaig, Trans.). New York: Columbia University Press.

Slow Food. (2006). About us: History. Retrieved November 18, 2007, from http://www.slowfood.com/about_us/eng/history.lasso.

Waters, A. (2001). Foreword. In C. Petrini, Slow food: The case for taste. (W. McCuaig, Trans.) (pp. vix-x). New York: Columbia University Press.

Waters, A. (2005). Fast-food values and slow food values. In Z. Barlow \& M.K. Stone (Eds.), Ecological literacy: Educating our children for a sustainable world (pp. 49- 55). San Francisco: Sierra Club Books. 